\title{
Research on the European and the United States Musical Compose Mode Development and the Influences on Computer Music in China
}

\author{
Sui Wu \\ Hunan City University, \\ Yiyang,Hunan,413000 China
}

\begin{abstract}
In this paper, we conduct research on the Europe and the United States musical composes mode development and the influences on computer music in China. All referrals audio music system and software audio sound is provided by the electronic sound, because of the different on the basis of the electronic storage manufacturing waveform sampling, the tone can be roughly divided into the orchestra instrument timbre, national band instrument timbre, the analog electronic band instrument timbre, tone and electronic composite timbres, these timbre features fully embodies the characteristics of electronic music tone splendor. Our research integrates the Europe and the United States musical composes mode to revise the traditional computer music pattern that is innovative.
\end{abstract}

Keywords- Computer Music, Europe and the United States, Compose Mode, China, Influence.

\section{Introduction}

Britain and the United States is musical the heyday of the country, from the perspective of the musical history, London's west end and Broadway in New York can be said as the birthplace of the musical. Musical supported by fascinating plot, with superb acting as foundation, with moving music and lithe and graceful dance form, as can make it become a kind of "inspire emotion and entertainment" to the person's "drama of work". Though the musical was grow up in Britain and the United States was born, but the extremely rich contemporary art form and strong entertaining made it is becoming all the countries in the world the audience like the performing arts [1-3].

According to the literature review, the characteristics of the music could be summarized as follows. (1) Crossover music means to attract more audience's interest in music style of a kind of adjustment, such as the style of two or more blended together, musicians in the hybrid behavior is common in the particular style in a different style of singing, playing activities. (2) Informally is singing, playing in different areas according to the need to change and become a new form of art, such as the classical musician involving national music or pop music. (3) Narrow concepts of cross-border singing that is involved in vocal music singing method of the cross and both phenomenon, in the form of singer to their singing techniques, singing style, and operation method of physiological function of control. (4) Artificially drawn based on vocal music singing, performance for singer about singing vocal music singing techniques, singing style and concept of the breakthrough, digest and cross of vocal music art style, penetration, transformation or the subversive. Cross-border singing means the same, across and beyond the singer with the different style of vocal music art phenomenon.

As a result of the general information transmission function of the new media with high technology content, the dissemination of information in the form of a free variety, rich content of comprehensive, fast, accurate, wide audience, therefore, soon be referenced in the field of education, become a part of the modern education technology. It will be based on the traditional education technology and new technology integration, transplantation, from technology, system technology and general multimedia technology to expand the resources performance technology, and finally, reach the role of facilitating learning and improving performance. Digital media teaching means for 
music teaching has brought the infinite possibility, breaking the previous single teaching model that showing the modern teaching idea of comprehensive, diverse and individual character characteristic.

In the digital music works, mastery of the emotion and aesthetic has a certain feeling, and took a serious attitude, good at will life interest naturally melt in work, and let your emotions and aesthetic in the digital display, not only deepen the comments of the age and the core reality, and improves the aesthetic taste of music, and reveal the rich connotation of oriental flavor, this is the meaning of the digital music young aesthetic subject consciousness. For better demonstration and illustration, in the figure one, we show the sample computer music software user interface [4-5].

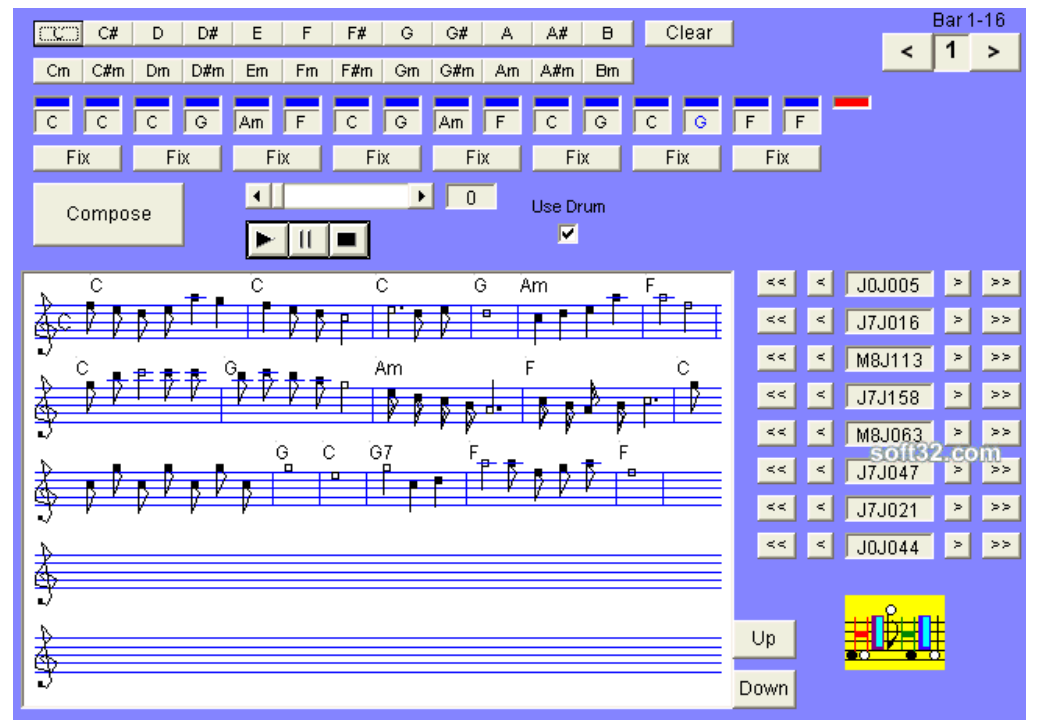

Figure 1. The Computer Music Software User Interface

In this paper, we conduct research on the Europe and the United States musical composes mode development and the influences on computer music in China. The world music culture and the world of general national culture associated with structural issues. The influence of cultural globalization environment for digital music and basic penetration, for the digital music with the world is a kind of complement and promote cultural system is not can finish in a few words. Digital music culture of the world once formed and then everywhere permeated by nationality music culture.

\section{Our Proposed Methodology}

The Europe and the United States Music. Music anthropology research object have everything from the start. Early comparative musicology, ethnomusicology "to" the national music of basic non-European system "as the main research object, the concrete content from the practicality of the British and American folk songs, Negro spiritual, native American jazz music, Musical Instruments, music to the theoretical sound high-handed, origin of the music, and said, the Eurocentric, etc. Later "urban ethnomusicology" and the "music" anthropology research object more expansion, the music widely involved in urban immigrant communities, urban professional music and karaoke bars such as pop music, and even involved in music history research. Ethnomusicology, so to speak, or music anthropology almost involved usually either all content of the concept. 
Of the national music at that early stage all feel that this subject has equal and musicology, it will eventually disappear and become musicology can reflect the content of the anthropology of the music professional knowledge mainly form of various works, its expression is the basic content of various kinds of theories, concepts and methods, and content is more emphasis on anthropology, ethnology and so on the knowledge of music subjects such as insiders and outsiders, such as field investigation and thought, behavior, conceptual and methodological content.

Europe and the United States crossover music has experienced the different historical development period, it contains culture trait is a certain fusion. Worthy of our attention is that the development of transboundary music has not only belongs to Europe and the United States, after a long period of the development, reference, adjustment, crossover music has become a worldwide art form. Crossover music is the perfect combination of various elements of music. It will be popular and classical music pop music symphony and poor of the elegant music crossover music ushered in a new era of music.

The Music Composing Modes. As the electronic technology and modern education technology in music education in the field of widely used, each course in the teaching means, teaching mode and teaching content constantly, constantly faced with the new challenges. So, in the terms of traditional composition teaching mode, how to deal with multimedia computer and Internet technology medium under the action of new media art phenomenon as is a must before composing music teachers ponder and research problems. Good music works can inspire people's morale and basic enterprising spirit. Therefore, the music is an integral part of people's life. With the progress of era and the development, composing music theory course teaching in colleges and universities should reform [6-7].

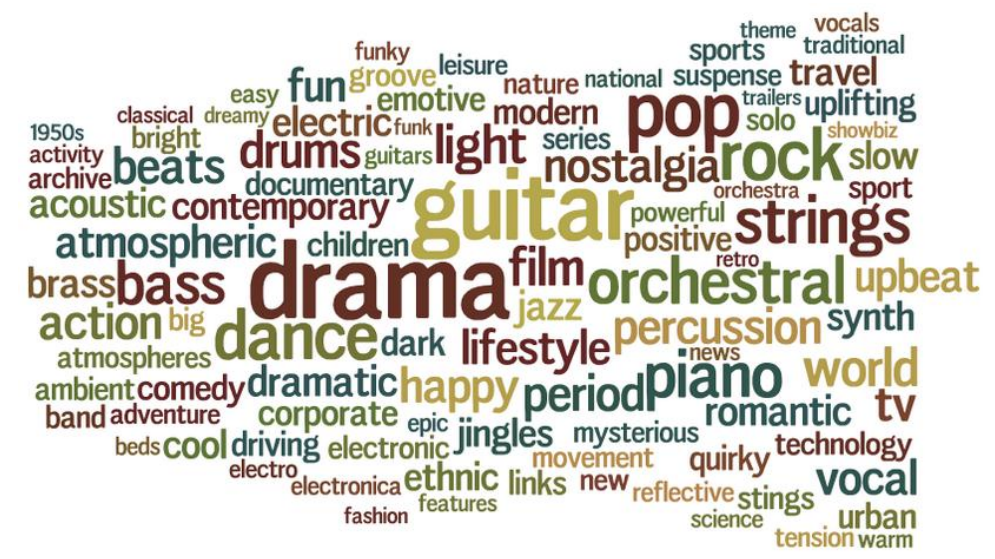

Figure 2. The Keywords and the Features of the Music Composing Modes

Many people think that European composer brings to us a small opera form is the core root of the musical development on Broadway. It with small opera coexist in the same time, in other words, it is also a farce and juggling the boom years and this dance is no plot, but also introduced a kind of the connection clues, no matter how small it is, may be more convenient to the so-called high society just kidding, take advantage of this drama or opera irony gimmick is funny, it simulates popular things.

While poets need to master the art of skilled techniques, and according to the requirements of a certain syllable, tone and rhythm, with concise language, abundant emotion and rich image to highly concentrated performance in social life and the human spirit world. It than fiction, drama and other large narrative literary style express out feelings more rich, more intense, so its artistic 
appeal to more powerful. One of the basic characteristics of music is good at lyrical. Songs as the combination of the poetry of chords law form, the song by using the words in expressing the characteristics of narrative with the ups and downs in the music melody, to be able to image vividly show the story of a typical environment that can also exhibit the typical deep feelings.

The Chinese Music. Due to the different Chinese and western aesthetics philosophy foundation as well as the differences in the national aesthetic psychology and resulting in the level of facial features and the position in aesthetic taste and value that has always has great differences. Different from its kind of art form, the characteristics of music art for its time and space as it is this characteristic that people thought in the history of music is very difficult to steady preserved to the present even save and variation rather than its general shape [8].

From a practical level, when the Chinese music culture in the general 20th century variation after transformation, especially embodied in the mainstream of urban form, have everywhere reflects the characteristics of the "new music culture", which is affected by the western professional music culture deep Chinese music culture. "Rhythm" in the music can exist without pitch alone constitutes a work, such as the sound of our traditional music ensemble music and African drum music. Because music can only in time, so melody can't independence from rhythm, no rhythm, only the pitch, timbre, or strength can't constitute any music works. Therefore, when discussing any kind of music, as problems than issues important in pitch, tone, and dynamics.

The depth of the western music main show is "deep" as China's music is characterized by "deep". Although both belong to the depth of the vehicle, but its inclusion and the effect are quite different. Rendered deep is mainly refers to music thinking reflected in a thought, an idea, an emotion, is in the terms of performance by the music theme in the deep mainly refers to the music of thinking in reverse reveal a kind of experience, a feeling, a kind of understanding, is in terms of peculiar to music charm.

With the change of idea, professional music workers began to western Musical Instruments, music theory, and the theory of composing technology acceptance, on the one hand is to the western music culture is introduced, on the one hand, carry on the processing of Chinese traditional music culture, this especially in the cities in China, influenced by the western music culture of the "new music" has become the mainstream of the Chinese music culture. After a century of integration from the music theory, harmony, orchestration, polyphony, counterpoint, etc. that receives from the west, forming the transformation in the field of music. In music colleges even the person engaged in traditional Chinese music, and starting from the basic music theory is fully accepted concept of western music.

The Computer Music. As most clearly reflects modern science and technology, computer music is the common product of music art and the core modern electronic technology. It was based on the computer, electronic high-tech music instrument is complementary, the development of computer music and music creation and production of the most powerful changes. Plays a role of inestimable importance on people's lives, strengthened the people love for music life. Science and technology to promote the music new change in mode of transmission, is the main person on ancient music. And social development today, the music is more of the computer integrated creation, production, and performing the three, to achieve the unity of the development of ideas and technology simplifies the process of making music to reduce the cost of music art spread, improved music benefits brought by the spread of in the market. In summary, the computer music has the following features.

- Music towards a higher level of general development, high-tech is required to adapt to the development of it. So technology increasingly developed today, the necessarily promote the progress of the music. At the same time, expand the scope 
of human activity, promoting the cultural communication, improve pleasure. With the development of science and technology, the music is in constant innovation, music art will toward a higher level development.

- Music need went up from sound, different equipment, different behavior that are also not the same, but its development is inseparable from the progress of science and technology, in order to better to express emotion in the music, we must need to use the means of science and the technology, to the technology beyond human to adapt to the development of it [9].

- Technology is the most obvious embodiment is the development of network technology as network has become indispensable tool in people daily life and work. Bring us a convenient, gradually into the science and technology in music teaching, to student's visual, auditory on all play a role of inestimable importance and also promote the development of the music itself.

\section{Conclusion}

In this paper, we conduct research on Europe and United States musical compose mode development and the influences on computer music in China. The electronic computer is advanced data processing equipment, more advantages. Besides can be extremely complex arithmetic, it has quick speed, high precision, large storage capacity such as the electronic computer can do all kinds of logical operations. Therefore, the highly effective information processing and analysis tools can be widely used in the various fields of music creation and music theory research. Lines the development of science and the technology of today, both society and individual creation or teaching, the modern music, more and more used in science and basic technology. Electronic musical instruments or many of the computer software are widely used in the making process of the music. Provide the convenience for more music enthusiasts, the creator as is the creative process is simple, more and more adapt to the needs of the science and technology society.

\section{Reference}

[1] Daly, Ian, et al. "Towards human-computer music interaction: Evaluation of an affectively-driven music generator via galvanic skin response measures." Computer Science and Electronic Engineering Conference (CEEC), 2015 7th. IEEE, 2015.

[2] Miranda, Eduardo Reck, and Julien Castet, eds. Guide to Brain-Computer Music Interfacing. London: Springer, 2014.

[3] McAdams, Stephen, and Roger Reynolds. "A Tribute to David Wessel (1942-2014) Consulting Editor for Music Perception, 1983-2008." Music Perception: An Interdisciplinary Journal 32.4 (2015): 434-436.

[4] Liu, Tsung-Ching, and I-Hon Lin. "Interactive Computer Music with Graphical Control by Using Android Phone for Audiovisual Installation Art Applications." (2013).

[5] Alexandraki, Chrisoula, and Rolf Bader. "Anticipatory Networked Communications for Live Musical Interactions of Acoustic Instruments." Journal of New Music Research (2016): 1-18.

[6] Lambert, Andrew, and Florian Krebs. "The Second International Workshop on Cross-Disciplinary and Multicultural Perspectives on Musical Rhythm and Improvisation." Computer Music Journal (2015).

[7] Mogensen, René, Nicolas Deletaille, and Alain Roudier. "The arpeggione and fortepiano of the 1820s in the context of 
current computer music." Early Music 42.4 (2014): 545-554.

[8] Wang, Cheng-I., and Shlomo Dubnov. "Pattern discovery from audio recordings by Variable Markov Oracle: A music information dynamics approach." Acoustics,
Speech and Signal Processing (ICASSP), 2015 IEEE International Conference on. IEEE, 2015.

[9] Lee, Sang Won, and Georg Essl. "Live coding the mobile music instrument." Ann Arbor 1001 (2013): 48109-2121. 